\title{
Analysis on Driving Forces of Sustainable Development of High-end Manufacturing Industry in China
}

\author{
Jun $\mathrm{Xu}^{1, \mathrm{a}^{*}}$ and Xingcheng $\mathrm{Ge}^{2, \mathrm{~b}^{*}}$ \\ Business School, Jiangsu Normal University, Xuzhou 221116 \\ almmxjxj@163.com ,'2269098517@qq.com
}

\section{Keywords: High-end manufacturing industry; Sustainable development; Driving forces}

\begin{abstract}
In recent years, with the development of economy and the progress of science and technology, the new wave of global industrial transfer, represented by high-end manufacturing industry, is becoming more and more intense. Nowadays, countries all of the world have increased the development of high-end manufacturing industry and developing high-end manufacturing industry will become an important driver of future economic development. This paper attempts to use Porter "Diamond" model to study the driving forces of sustainable development of high-end manufacturing industry in China, and then divides the driving forces into positive driving force and reverse driving force according to the dimension. Through the analysis, we think that our country should continue to strengthen the development of the positive driving force; try to improve the reverse driving force and take advantage of the strengths and circumvent the weaknesses, so as to promote the sustainable development of our high-end manufacturing industry.
\end{abstract}

\section{Introduction}

In 2017, the party's 19th CPC National Congress report mentioned: "accelerate the construction of manufacturing power, accelerate the development of advanced manufacturing; support the optimization and upgrading of traditional industries and aim at raising the level of international standards in order to promote our industry to the global value chain to the high-end and cultivate a number of world-class advanced manufacturing clusters." Therefore, our country should increase the development of high-end manufacturing according to five development concepts, including the national innovation, coordination, green, open, sharing. High-end manufacturing industry is the core link of high-end industrial chain and it is at the top of the value chain, with the characteristics of high technology, high added value, high risk, high income etc. ${ }^{[1]}$ At present, our country is increasing the development of high-end manufacturing, and has formed a certain scale of industrial agglomeration area ${ }^{[2]}$.

Although our country is a manufacturer of quantity, it is not a manufacturing power. The core technology of manufacturing industry and the brand of products are restricted by the enterprises of developed countries. At present, the domestic research on the high-end manufacturing industry in our country is mainly about its development predicament and the countermeasure research and the research on the high-end manufacturing industry influence factor is relatively few: Zhengchu $\mathrm{He}(2015)^{[3]}$ believed that Chinese manufacturing industry, which relies on the traditional "factors driven" (such as raw materials, labor force and other factors to gain competitive advantage), is making the development advantage of manufacturing industry decline gradually. Practice has proved that the mode of development of extensive manufacturing industry is not sustainable; Yuanyuan Tan $(2016)^{[4]}$ used factor analysis method to explore the current situation of the global influence of China's manufacturing industry deeply by selecting the sample data of the top 35 countries in 2014. The study showed that the global impact of China's manufacturing industry ranked 10th out of the 35 samples selected and then the author used the panel data to analyze the key factors of the global influence of China's manufacturing industry scientifically. The results showed that the innovation, profitability and green development have a significant impact on the global impact of China's manufacturing industry.

This paper attempts to use Porter "Diamond" model to study the driving forces of the sustainable 
development of high-end manufacturing industry in China, and classify the driving forces according to the dimensions, which can be divided into positive driving force and reverse driving force. Through the deep analysis of positive and reverse driving forces, it is concluded that the sustainable development of high-end manufacturing industry in our country needs the joint action of positive and reverse driving forces.

\section{Construction of driving force model for sustainable development of high-end manufacturing industry}

We can use the following methods to analyze the driving forces of sustainable development of high-end manufacturing industry, such as the regression, the principal component, the Porter "diamond" model, factor, SPSS software and so on. In this paper, to simplify the steps, we choose Porter "Diamond" model to analyze the driving forces of the sustainable development of high-end manufacturing industry in China.

The Porter "diamond" model is also known as the "diamond" theory, the national competitive advantage theory and so on. Michael Porter, a famous strategic management scientist at Harvard University, put forward this model in 1990. The model is mainly used to analyze the basic competition situation of a certain industry and has strong influence in the world. See fig. 1:

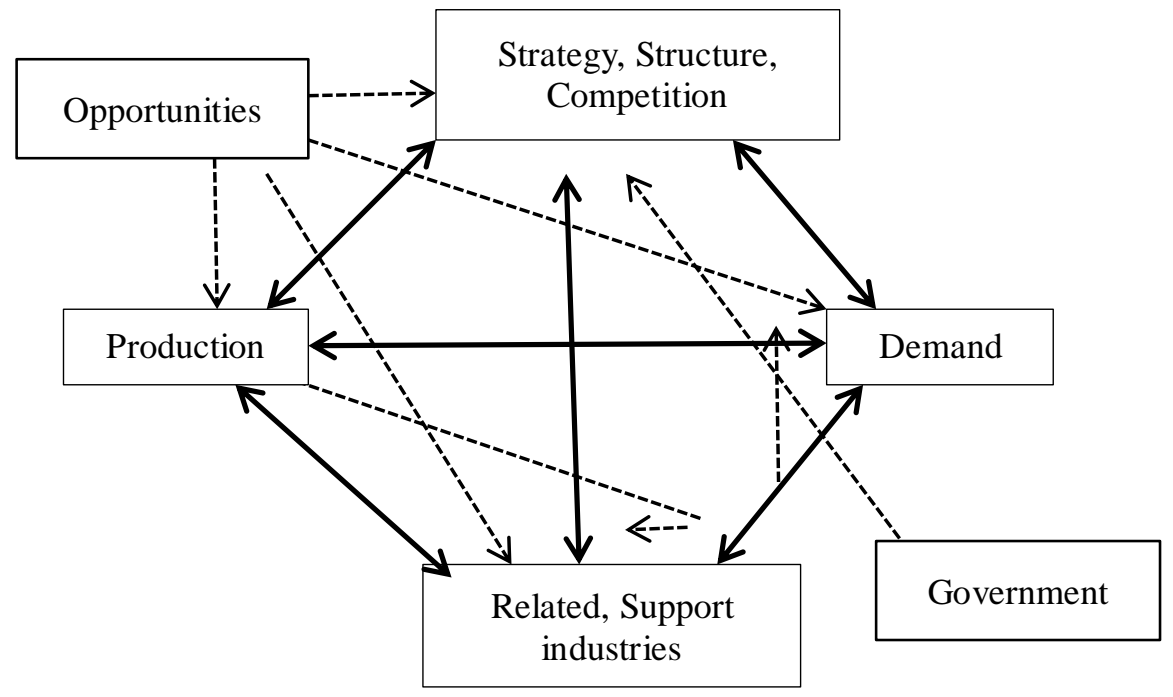

Figure 1. The Porter "diamond" model

As can be seen from figure 1, Porter's "diamond" model theory holds that the following six factors will have an impact on the development of the industry: factors of production, conditions of demand, and enterprise strategy, structure and peer competition, related and support industries, opportunities, governments. These factors interact and influence each other to form different industrial forms ${ }^{[5]}$.

The factors of production mainly include human resources, knowledge resources, capital resources, and infrastructure and so on; the demand factor mainly refers to the market demand of products and services; the related and supporting industries are the important reference conditions to evaluate the sustainable development of a certain industry. It refers to whether these industries and related upstream enterprises have international competitiveness. Enterprise strategy, structure and peer competition refer to the tractive force of international market demand and the thrust of domestic competitors; The opportunity refers to the opportunity and the challenge, in order to seek the technical breakthrough, the enterprise finds its own development advantage from the change of the external policy environment; As the leading factor of the industry, the main function of the government is to issue and formulate policies and plans and to balance the coordinated development of the industry. The six elements are drawn like a diamond on the map, so it's called a "diamond" model. 
Opportunities can be met but not available. Although opportunities cannot be measured, as long as we can grasp the market demand fully; understand market operation trends, and strengthen cooperation with industry, as well as domestic and foreign relations, it is also possible to predict opportunities. Therefore, opportunities can also be a factor in the development of industry. In the process of sustainable development of industry, we cannot ignore the role of government. It plays a role in promoting and stimulating the creative desire of enterprises. Under the policy of the government, the industry can develop rapidly and efficiently. Therefore, in this paper, the government also as an important factor to analyze.

\section{Analysis on the driving Forces of the Sustainable Development of High-end Manufacturing Industry in China}

Above, through figure 1, Porter's "diamond" model is described in detail, and it is concluded that factors of production, demand, opportunities, government etc. will have a certain impact on the development of the industry. However, everything has two sides. That is, in the process of the development of high-end manufacturing, some driving forces play a promoting role in its development, while some driving forces will hinder the development of high-end manufacturing. Therefore, this part divides Porter's "diamond" model into positive driving force and reverse driving force according to dimension, to explore the driving force of sustainable development of high-end manufacturing industry in China. Details are shown in fig. 2:

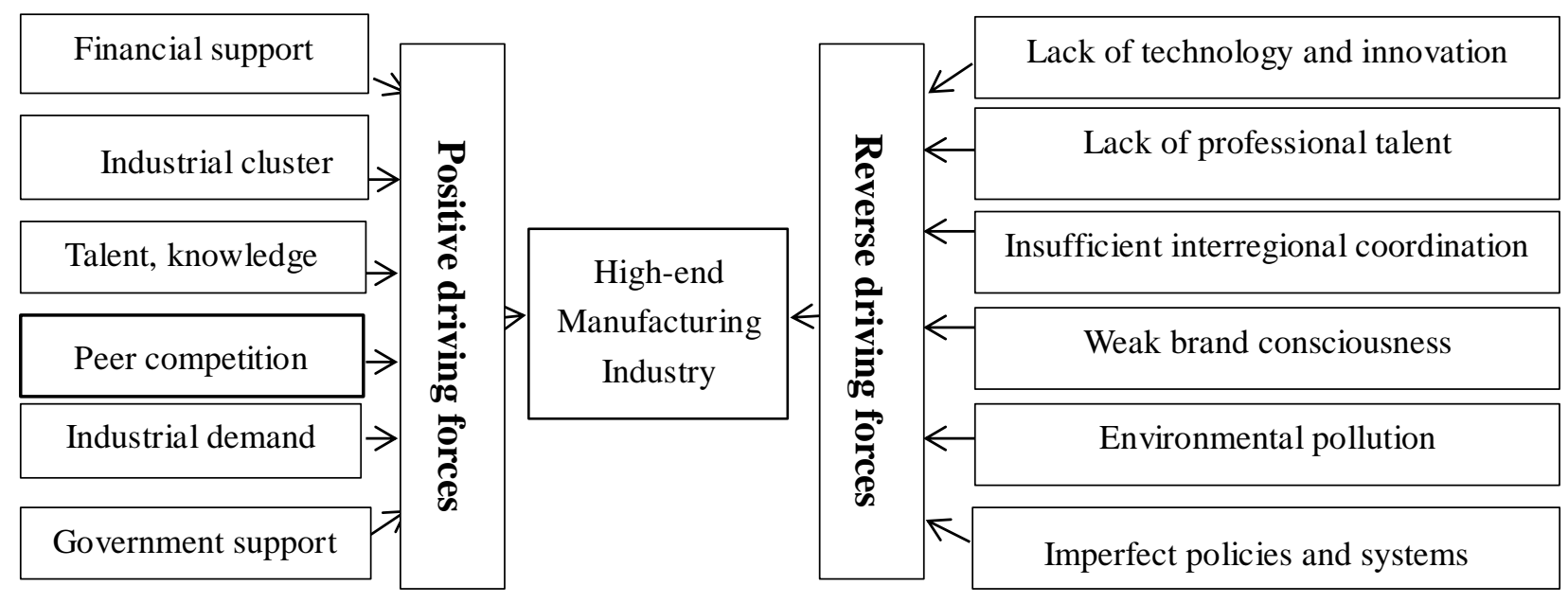

Figure 2. Driving force model of high-end manufacturing industry

\section{Analysis on Positive Driving Force.}

Financial support. "Made in China 2025"plan, which was issued by the State Council in 2015 defines the development direction of China's advanced manufacturing industry. In 2017, 19th CPC National Congress mentioned clearly, we should speed up the construction of manufacturing power; speed up the development of high-end manufacturing; promote our industry to the high global value chain and cultivate the world high-end manufacturing cluster. In recent years, our country pays more and more attention to the development of high-end manufacturing industry. The development of high-end manufacturing industry can not only enhance the national economic strength, but also is an important way to enhance the national hardware strength. Accordingly, our country increases the capital investment to the high-end manufacturing industry, raises the research funds of the strategic emerging industries unceasingly, such as the high-end manufacturing industry. From the central to the local, the financial support of the government is also increasing year by year, and the intensity of investment is also increasing, which provides financial guarantee for the development of high-end manufacturing industry. Therefore, whether in the key position of high-end hardware equipment or other supporting industrial chain structure, we can carry out high-tech research and application. 
Industrial cluster. Porter believed that the development and progress of any industry cannot rely on its own efforts to obtain, and in order to achieve the sustainable development of the industry, it needs to cooperate with other upstream and downstream enterprises. Similarly, the development of high-end manufacturing industry cannot be separated from its related industries between the benign cooperation, but also inseparable from the upstream and downstream industries, which provide it with productive services.

In recent years, our country is upgrading the traditional manufacturing industry to the high-end manufacturing industry gradually. It will make the high-end manufacturing industry chain structure to the direction of rationalization through continuous efforts. In accordance with the development trend of vertical integration, the enterprises accelerate the development of high-end manufacturing parts and core products; increase the added value of products, and strengthen exchanges and cooperation with upstream and downstream industries constantly; promote the development of high-end manufacturing industry better. Furthermore, through the horizontal integration of enterprises, we should expand the scale of enterprises; improve the variety and width of products, the scattered related industries together; integrate industrial clusters, form the agglomeration effect. This can not only reduce the operating costs of high-end manufacturing, but also optimize the allocation of elements, and improve the competitiveness of the industry effectively. While developing all areas of high-end manufacturing in an all-round way, we should focus on selective development ${ }^{[6]}$.

In the development of high-end manufacturing industry, it continues to extend to various industries, such as medical security, public infrastructure construction, modern home and other industries, which is not only the strategic level of high-end manufacturing progress, but also plays a more important role in serving the society and changing people's way of life. Therefore, with the interaction between upstream and downstream factors, the high-end manufacturing has a great potential for development, which will promote the rapid and steady development of high-end manufacturing.

Talent, knowledge resource. In recent years, in knowledge and technology, high-end manufacturing enterprises are developing forward too. They continue to learn new knowledge and technology; apply it to all aspects of high-end manufacturing development and form their own core technology. For example, Dalian Shipbuilding Heavy Industry is famous for producing ships. It has the largest production workshop in China and the most competitive high-end production technology, which is a shipbuilding enterprise with modern characteristics. Many production fields of Shenfei Group are in the leading position in China, such as aircraft manufacturing, numerical control machining of large composite structural parts and so on. All these show that good knowledge resources can promote the development of industry better.

On the other hand, we should give more attention on the leading role of the backbone enterprises in the industry and the basic role of institutions of higher learning and scientific research institutes; strengthen the cooperation with colleges and universities, and concentrate on the technological research and theoretical innovation of high-end manufacturing industries. It is necessary to perfect the mechanism for the introduction of talents in the field of manufacturing and attract talents from domestic and foreign specialized fields with superior conditions, and improve the overall knowledge quality of high-end manufacturing personnel constantly. We should make the high-end manufacturing industry employees continue to increase. Their knowledge, skills and R \& D level also tends to a higher level year by year; develop into a global first-class team gradually, which promote the development of the high-end manufacturing industry.

Peer competition drive. From many theories and practices, we can see that maintaining a good competitive advantage between related industries can promote the development of industry effectively. There is fierce domestic competition among high-end manufacturing enterprises. Fierce competition can lead enterprises to seek ways to improve production efficiency and upgrade manufacturing technology. This, in turn, encourages them to develop from domestic competitors to better international competitors. Domestic competition has brought a series of pressures to enterprises, including innovation, improving product quality, reducing production costs and so on. 
These pressures have helped to generate high-end manufacturing firms that are competitive in the world. With the continuous improvement of industrial chain structure, high-end manufacturing industry is also developing towards the direction of cluster and industrialization gradually.

Increasing industrial demand. Porter believed that the driving force of industrial development is to predict demand in the domestic market accurately. It is found that the difference between the domestic market and the international market is that the enterprises can predict the customer demand of the domestic market in time, which is beyond the ability of the foreign competitors. However, with the global competition becoming more and more intense, the importance of the domestic market does not decline, but becomes more important.

There is no doubt that the development of industry is to meet the needs of the market. If an industry wants to develop for a long time and become a pillar industry of a region, it must make the development direction of the industry according to the direction of market demand. In recent years, with the economic transformation and the continuous upgrading of industrial structure, the products produced by the traditional manufacturing industry can no longer meet the increasing demand of the market. The increase of industrial demand has promoted the upgrading of traditional manufacturing industry to high-end manufacturing industry, which is the opportunity and challenge of developing high-end manufacturing industry in China.

Government support. On the one hand, the government can play a leading role in the development of industry. Through the investigation of the overall environment of the domestic market, the government has formulated some laws and regulations, deepened the reform of the system, balanced the overall operation of the market, and provided a fair and reasonable competitive environment for the development of high-end manufacturing industry. On the other hand, government policy will have a direct impact on the development of high-end manufacturing. The government influences the competition among enterprises through some capital market regulations, tax policies and other means. Therefore, the government's laws, regulations, policy guidance and financial support have promoted the sustainable development of high-end manufacturing industry ${ }^{[7]}$.

\section{Analysis on Reverse Driving Force.}

Lack of core technology and innovation capability. Insufficient innovation ability and lack of core technology are two important factors, which restrict the development of high-end manufacturing industry in China. Some enterprises do not invest enough in the research and development of new products and new technology, which lead to less original technological innovation and lack of re-innovation of imported technology when absorbing foreign advanced technology and the ability of secondary development is not strong, so that enterprises will fall into a vicious circle of "introduction-backwardness-reintroduction -backwardness". In addition, our country's high-end manufacturing enterprises rely on foreign advanced technology, which mainly rely on the introduction of foreign advanced technology, through the assembly of products. The technical content and added value of the products produced are relatively low. All of these affect the sustainable development of high-end manufacturing industry to a large extent.

Lack of professional talent. Talent is the key factor for the long-term development of an enterprise. Without talent, there will be no advanced technology and theory, and there can be no perfect market. A person who has the ability of leadership can lead a good innovation team, can drive the development of a new industry; can promote the formation of a new economic growth point. Without first-class professionals, there can be no first-class industry. Therefore, in the process of the development of high-end manufacturing industry, we need more professional talents to promote the development of the industry. However, in most high-end manufacturing enterprises of our country, the proportion of professional personnel is very small and the knowledge level of most personnel is limited. So it is difficult to apply the advanced theory to the production of high-end manufacturing industry. This has led to the slow growth of high-end manufacturing enterprises and the growing gap with developed countries ${ }^{[8]}$.

Insufficient interregional coordination. In the process of economic development, quite a number of regions have followed the path of "complete categories and self-contained systems" in 
our country. Instead of developing their economies according to their own advantages of resources, they are engaged in "large and complete, small and complete." The phenomenon of industrial isomorphism among regions is serious, which is prominent in the high-end manufacturing field. Some high-end manufacturing enterprises do not attach importance to regional coordination and cooperation; they only consider short-term interests and ignore their long-term development. Due to their own affairs, the lack of specialized division of production between regions, it is difficult to make full use of their respective advantages, complementary functions, to form an effective force to promote the development of high-end manufacturing. This has also affected the development of high-end manufacturing seriously ${ }^{[9]}$.

Weak brand consciousness. With the development of economic globalization, most countries in the world are making more and more efforts to build their own international brands. A good international brand not only represents the name, quality and concept of this product. Fundamentally, it also represents the cultural concept of a country and plays a role in propagating its own cultural point of view, enhancing communication with the world and spreading human civilization. However, at present, the quantities of the world brands are very few in our country and the competition ability of brand is not high. Because of the small number of patents obtained by Chinese enterprises, it leads to a great gap with the big state of innovation. In addition, lack of the ability of innovation and weak brand consciousness are also the significant factors. If this continues, it will makes the international influence of our manufacturing industry very limited, which restricts the globalization of high-end manufacturing industry ${ }^{[10]}$.

Waste of resources, environmental pollution. With the sustainable and rapid development of economy, energy consumption and environmental pollution, which are caused by the continuous upgrading and the transformation of manufacturing industries, have become the focus of our country. It is mainly the industry with high energy consumption and high pollution. It has the characteristics of low utilization of resources and high emission intensity. Especially in recent years, the phenomenon of industrial isomorphism in manufacturing industry has led to a large number of waste of resources and the decline of environmental carrying capacity and other serious consequences. Nowadays, air pollution, water pollution and some heavy metal pollution have become the main focus of the society. In the process of sustainable economic development, our country is faced with more serious problems, such as low utilization of resources, energy resources, and serious environmental pollution and so on. These problems are a huge pressure and challenges for our high-end manufacturing industry ${ }^{[11]}$.

Imperfect policies and systems. High-end manufacturing industry has the characteristics of high technology content, high added value, high income, strong driving force, and some also has the characteristics of high investment and high risk. In order to ensure the development of high-end manufacturing industry, this requires government and policy support. However, in the current government policy system, the support for high-end manufacturing is not very strong, including the following three aspects: first, the market environment is more complex. In the development of high-end manufacturing industry, there are some problems, such as insufficient market cultivation, backward infrastructure, untimely formulation of relevant technical standards, disorder of market order, and so on. Second, the investment and financing system is not perfect. In our country, the investment scale of some entrepreneurial enterprises is relatively small; the financing guarantee institutions are few; the guarantee system is not perfect, and so is the high-level capital market system. For some start-up, growth innovation enterprises, financing is difficult, capital bottleneck constraints are obvious. Third, the financial and tax support is not enough. The investment of government financial funds is too scattered ; the financial and tax support is insufficient; the way of support and the establishment of some policy systems need to be further improved, and the implementation of policies is not in place, such as government procurement, research and development investment deduction etc. .

Therefore, in order to enable the sustainable development of our high-end manufacturing industry, we should continue to increase the development of positive driving forces, and try to improve the reverse driving force, for example, introducing advanced talents and technology at 
home and abroad, strengthening interregional coordination, attaching importance to the brand construction of high-end manufacturing industry, focusing on the green development of high-end manufacturing industry, improving the high-end manufacturing support system and so on. We should let the positive driving force and the reverse driving force interact; promote the strengths and circumvent the weaknesses, and realize the sustainable development of the high-end manufacturing industry in our country.

\section{Conclusions}

High-end manufacturing industry is the foundation of national economy and is the important embodiment of economic strength. This paper attempts to use Porter "Diamond" model to analyze the driving force of sustainable development of high-end manufacturing industry in China, and divides the driving force into positive driving force and reverse driving force according to the dimension. The positive driving forces include: financial support, industrial agglomeration, talents, knowledge resources, peer competition driving force, increasing industrial demand, government support and so on; the reverse driving force includes: core technology, lack of innovation ability, lack of professionals, lack of inter-regional coordination, weak brand awareness, waste of resources, environmental pollution, policy, system imperfection etc.. Through the analysis, we think that if developing the high-end manufacturing industry rapidly, we should continue to increase the development of positive driving force, and try to improve the reverse driving force, so as to promote the sustainable development of high-end manufacturing industry in China.

\section{Acknowledgment}

This research was financially supported by National Social Science Foundation (Grant No. 16BJY042).

\section{References}

[1] Y. Liu: Productivity research, Vol. 35 (2011) No.3, p.92-94. (In Chinese)

[2] X.H. Chen and Y. Zhong: Industrial technology economy, (1994) No.6, p.25-32. (In Chinese)

[3] Z.C. He and H.Y. P: J. of Changsha University of Technology (Social Sciences Edition), Vol. 30 (2015) No.3, p.103-110. (In Chinese)

[4] Y.Y. Tan: Research on the influence factors and cultivation path of the Global influence of China's Advanced Manufacturing Industry (MS., Guangzhou University of Technology, China 2016).p.32-44. (In Chinese)

[5] Y.Y. Zhao: Research on influencing factors and Countermeasures of High-end equipment Manufacturing Industry in Liaoning Province (MS., Tianjin University of Finance and Economics, China 2014).p.26-38. (In Chinese)

[6] S. Han: Management manager, (2017) No.3, p.199. (In Chinese)

[7] H.Y. Zhang: Economic research journal, (2012) No.29, p.29-30. (In Chinese)

[8] G. Zhao: Contemporary economic management, Vol. 36 (2014) No.10, p.64-68. (In Chinese)

[9] K. Li, B. Yu and Q.J. Li. International Conference on Multimedia, Communication and Computing Application (Guangzhou, China, April 13-15, 2015).p.55-60

[10] Y. Zhou and C.L. Han: Industrial economy, Vol. 33 (2012) No.1, p.27-31. (In Chinese)

[11]X.F. Lin: J. of Fuzhou party school, (2016) No.2, p.52-55. (In Chinese) 